\title{
Successful resolution of left ventricular thrombus with apixaban treatment
}

\author{
Erkan Yildirim, Kamuran Kalkan *, Emrah Ipek, Selami Demirelli, Emrah Ermiş \\ Department of Cardiology, Erzurum Region Training and Research Hospital, Erzurum. Turkey
}

\section{A R T I C L E I N F O}

\section{Article history:}

Received 26 November 2015

Received in revised form 23 December 2015

Accepted 23 December 2015

Available online 5 March 2016

\section{Keywords:}

New oral anticoagulants

Left ventricular thrombus

Myocardial infarction

\begin{abstract}
A B S T R A C T
A 68 years old male patient with history of dyslipidemia and smoking was admitted to our emergency department with complaint of dyspnea. He was transferred to the coronary care unit with the pre-diagnosis of acute coronary syndrome. In his transthoracic echocardiography, we detected anterior, anterior septal and apical wall akinesia with an LV ejection fraction (EF) of $25 \%$, moderate mitral regurgitation and $13 \times 6 \mathrm{~mm}$ sized thrombus in the LV. Apixaban treatment $5 \mathrm{mg}$ po bid was started. In the second month transthoracic echocardiograpy, the thrombus in LV was found to have disappeared. In this report we present a patient whose LV thrombus was successfully treated after myocardial infarction by apixaban.

(c) 2016 The Society of Cardiovascular Academy. Production and hosting by Elsevier B.V. All rights reserved. This is an open access article under the CC BY-NC-ND license (http://creativecommons.org/licenses/by-nc-nd/4.0/).
\end{abstract}

\section{Introduction}

Left ventricular thrombus is usually seen in situations with reduced left ventricular (LV) function including dilated cardiomyopathy and LV aneurysms or after myocardial infarction (MI). ${ }^{1}$ In observational studies and meta-analyses, anticoagulant therapy is recommended in order to minimize embolization risk. ${ }^{2,3}$ An oral vitamin $\mathrm{K}$ antagonist, warfarin, has been being used as an anticoagulant for this purpose for a long period of time. New oral anticoagulants (NOACs: dabigatran, rivaroxaban, apixaban, etc.) were found to be non-inferior or superior compared to warfarin in prevention of thromboembolism in patients with nonvalvular atrial fibrillation. ${ }^{2}$ Nevertheless, the data about the role of new oral anticoagulants in the management of LV thrombus is deficient.

\section{Case report}

A 68 years old male patient with history of dyslipidemia and smoking was admitted to our emergency department with complaint of dyspnea. The ECG was in sinus rhythm and there were precordial T wave negativity. In his initial evaluation, the consecutive two troponin levels were greater than the upper reference limit. After then he was transferred to the coronary care unit with the pre-diagnosis of acute coronary syndrome. In his transthoracic echocardiography, we detected anterior, anterior septal and apical wall akinesia with an LV ejection

\footnotetext{
* Corresponding author at: Department of Cardiology, Erzurum Region Training and Research Hospital, 25100 Erzurum, Turkey. Tel.: + 9044223255 55; fax: +90 442232 5025 .

E-mail addresses: drerkan23@yahoo.com (E. Yildirim), Kalkankamuran@yahoo.com (K. Kalkan), dremrah21@yahoo.com (E. Ipek), demirelli23@yahoo.com (S. Demirelli), emr_ermis@hotmail.com (E. Ermiș).

Peer review under responsibility of The Society of Cardiovascular Academy.
}

fraction (EF) of $25 \%$, moderate mitral regurgitation and $13 \times 6 \mathrm{~mm}$ sized thrombus in the LV (Fig. 1). The thrombus was detected to be mobile and attached to the distal portion of the anterior septum. The D-dimer level was greater than the upper reference level. In coronary angiography, left anterior descending artery was found to be totally occluded in its ostium. In positron emission tomography, the anterior wall was detected to be non-viable. As a result, the patient was decided to be managed medically. Aspirine $100 \mathrm{mg}$ po qd, clopidogrel $75 \mathrm{mg}$ po qd and warfarin $5 \mathrm{mg}$ po qd were prescribed and then he was discharged. The patient did not come for early outpatient visit for measurement of international normalized ratio (INR). After 30 days of discharge, he was admitted to our outpatient clinic with gastrointestinal (GI) bleeding. In his laboratory examination, he was found to have an INR of 10. Then, he was hospitalized and the warfarin was stopped. Both upper and lower GI endoscopy were performed by gastroenterology clinic and there was not any active bleeding points in the gut. The bleeding was considered to be due to warfarin overdose. During follow up, the patient was hemodynamically stable. In the control transthoracic echocardiograpy, the thrombus was found to be persisted with its previously measured dimensions. His body weight and creatinine level were in suitable range for apixaban treatment (weight:72 kg and creatinine: $0,9 \mathrm{mg} / \mathrm{dl}$ ). Since the patient was non-compliant and could not tolerate warfarin therapy, apixaban $5 \mathrm{mg}$ po bid was started. In the second month transthoracic echocardiograpy, the thrombus in LV was found to be disappeared (Fig. 2).

\section{Discussion}

In this report we present a patient whose LV thrombus was successfully treated after myocardial infarction by apixaban. LV thrombus after MI is related to worse prognosis and increased thromboembolic risk. ${ }^{3}$ 


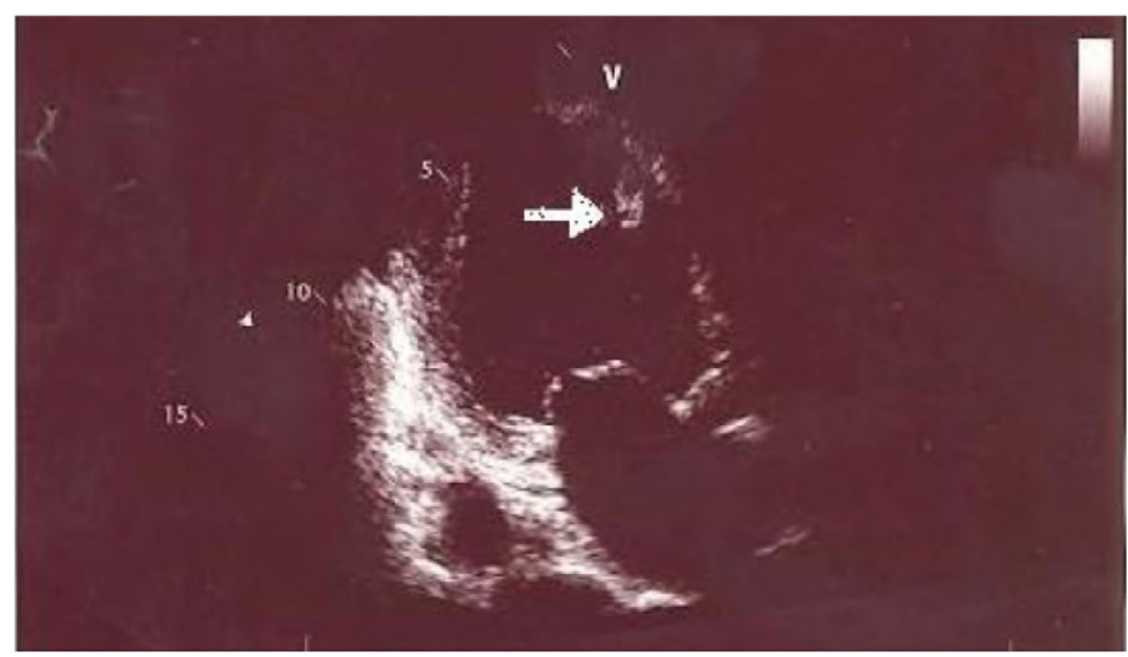

Fig. 1. Two dimensional echocardiogram shows left ventricular apical thrombus $(13 \times 6 \mathrm{~mm})$.

Anticoagulation with dual antiplatelet therapy (triple antithrombotic therapy) increases bleeding risk substantially. ${ }^{4}$ As a result, time of initiation and duration of triple antithrombotic therapy should be adjusted according to the atherothrombotic, cardioembolic and bleeding risk of the patients. Our patient had triple therapy for one month because of high bleeding risk (HAS-BLED score greater than 2$).{ }^{4}$ After one month, clopidogrel has stopped and we have continued with aspirin and apixaban. LV thrombus resolution with warfarin therapy was demonstrated in some previous observational studies and meta-analyses. ${ }^{3,5}$ The role of new oral anticoagulants in reducing thrombo-embolic risk in patients with LV mural thrombus is needed to be clarified. The slow onset of action, need for dose adjustments and regular monitoring to provide adherence to the narrow therapeutic range, dietary restrictions, and multiple drug interactions limit the use of vitamin K antagonists. ${ }^{6}$ NOACs do not have these kind of limitations and may also reduce the risk of hemorrhagic stroke. ${ }^{6}$ In the ARISTOTLE trial, apixaban was shown to have superior efficacy in reducing stroke, systemic embolism, and all cause mortality compared to warfarin. ${ }^{7}$ In 2014 American Heart Association stroke guidelines, NOACs are recommended for three months in patients with LV mural thrombus intolerant to warfarin with a new class $2 \mathrm{~b}$ recommendation and a level of evidence $C{ }^{8} \mathrm{We}$ stopped warfarin and started apixaban in our patient because of highly increased supratherapeutic INR and gastrointestinal bleeding. In the second month of therapy, LV thrombus was found to be completely resolved.

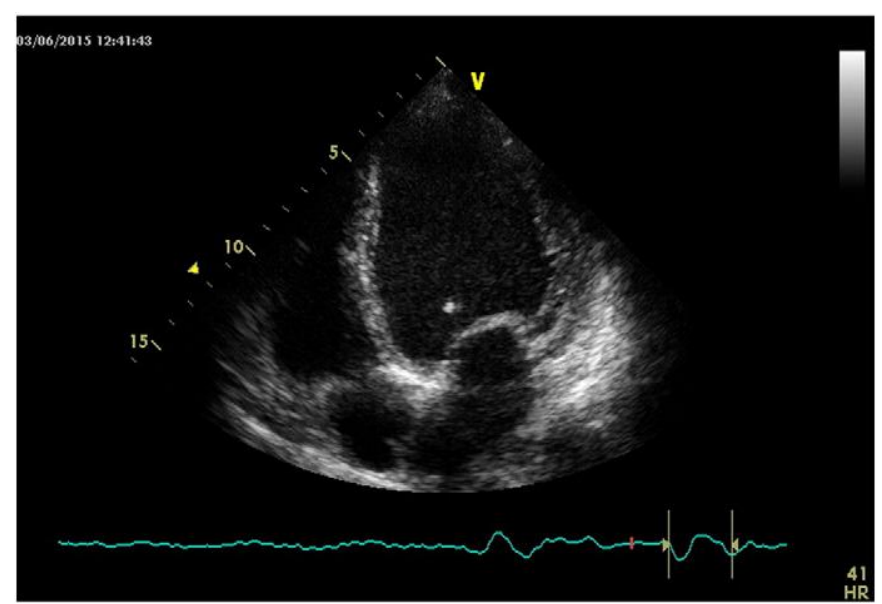

Fig. 2. Apical mural thrombus resolved completely after 8 weeks treatment with apixaban.
There are several limitations of the use of NOACs. The careful use in elderly and patients with renal impairment is recommended. ${ }^{9}$ The data is scant regarding the use of NOACs in pregnant women, pediatric patients and the patients with valvular disease. ${ }^{9}$ Except dabigatran, the absence of approved antidotes in the case of life-threatening hemorrhage or surgery is another limitation for their use. ${ }^{9}$

In conclusion; our case showed that LV thrombus can be successfully treated by apixaban. However, randomized clinical trials are needed in order to elucidate and confirm the use of NOACs as an alternative to warfarin.

\section{Conflict of interest}

The authors declare that they have no conflicts of interest related to the publication of this manuscript.

\section{References}

1. Haugland JM, Asinger RW, Mikell FL, Elsperger J, Hodges M. Embolic potential of left ventricular thrombi detected by two-dimensional echocardiography. Circulation 1984;70:588-598.

2. Heidbuchel H, Verhamme P, Alings M, et al. European Heart Rhythm Association practical guide on the use of new oral anticoagulants in patients with non-valvular atrial fibrillation. Europace 2013;15(5):625-651.

3. Vaitkus PT, Barnathan ES. Embolic potential, prevention and management of mural thrombus complicating anterior myocardial infarction: a meta-analysis. J Am Coll Cardiol 1993;22(4):1004-1009.

4. Windecker S, Kolh P, Alfonso F, et al. 2014 ESC/EACTS guidelines on myocardial revascularization: the task force on myocardial revascularization of the European society Of cardiology (ESC) and the European Association for cardio-thoracic surgery (EACTS)developed with the special contribution of the European association Of percutaneous cardiovascular interventions (EAPCI). Eur Heart J 2014;35(37):2541-2619.

5. Nadareishvili ZG, Choudary Z, Joyner C, Brodie D, Norris JW. Cerebral microembolism in acute myocardial infarction. Stroke 1999;30(12):2679-2682.

6. Savelieva I, Camm AJ. Practical considerations for using novel oral anticoagulants in patients with atrial fibrillation. Clin Cardiol 2014;37:32-47.

7. Granger $\mathrm{CB}$, Alexander JH, McMurray JJ, et al. Apixaban versus warfarin in patients with atrial fibrillation. N Engl J Med 2011;365(11):981-992.

8. Kerman WN, Ovbiagele B, Black HR, et al. Guidelines for the prevention of stroke in patients with stroke and transient ischemic attack: a guideline for healthcare professionals from the American Heart Association/American Stroke Association. Stroke 2014:45(7):2160-2236.

9. Hanley CM, Kowey PR. Are the novel anticoagulants better than warfarin for patients with atrial fibrillation? J Thorac Dis 2015;7(2):165-171. 